\title{
La libertad cristiana en la relación cristología-antropología según la teología de Walter Kasper
}

\author{
JUAN PÉREZ NÚÑEZ \\ Universidad Católica del Maule (Chile) \\ jperez@ucm.cl
}

\begin{abstract}
Resumen
Este artículo se desarrolla en diálogo con la modernidad, reconociendo en el quehacer teológico de Walter Kasper un ejemplo de acogida crítica y positiva del concepto de «sujeto moderno», aunque sin desconocer sus raíces cristianas. En palabras de Kasper, la cristología sobrepuja la antropología. El hombre es el sujeto que recibiendo el ser en libertad, vive como una esencia abierta que encuentra en el Dios de Jesucristo y en el Verbo encarnado la concreción máxima de la humanidad nueva. Al reconocer a la persona de Jesucristo como el «universal concreto», el hombre encuentra caminos de humanización plena, a través de una libertad obediente que en Jesucristo manifiesta su total disponibilidad al Padre y a los hombres.
\end{abstract}

Palabras claves: sujeto moderno, Jesucristo, preexistencia, proexistencia, libertad, esencia abierta.

\section{Christian freedom in the relationship between$$
\text { Christology-antropology }
$$$$
\text { according to Walter Kasper theology }
$$

\begin{abstract}
This article is developed in dialogue with modernity, recognizing in the theological doing of $W$ alter Kasper an example of positive and critical reception of the concept of the «modern subject», but without ignoring its Christian roots. In Kasper's words, Christology over-pushes anthropology. Man is the subject that receiving his being in freedom, lives it as an open essence that finds in the god of Jesuschrist and in the verb make it flesh the biggest realization of the new bumankind. Recognizing the person of Jesus Christ as the «concrete universal», man finds full path of bumanization through obedient freedom in Jesus Christ expresses its full availability to the Father and to men.
\end{abstract}

Key words: modern subject, Jesuschrist, pre-existing, pro-existing, freedom, open essence.

Sacerdote de la Diócesis de Linares. Licenciado en Ciencias Religiosas por la Universidad Católica del Maule y Magíster en Teología por la Pontificia Universidad Católica de Chile. Profesor de Teología Dogmática en la Facultad de Ciencias Religiosas y Filosóficas de la UCM y en el Seminario San Pablo de Rauquén de la Diócesis de Talca. 


\section{Introducción}

El presente artículo es una reflexión que aborda la pregunta en torno a cuáles serían las condiciones o presupuestos antropológicos que la teología, y particularmente la cristología, suponen a la hora de mostrar la novedad del mensaje cristiano, sobre todo en la época moderna. Nos referimos a aquellos antecedentes de tipo antropológico-filosóficos, del diálogo rico y necesario, que debe existir entre la reflexión creyente y la cultura, entre el mensaje cristiano y la época moderna, la que ha experimentado un giro antropológico que desafía a la fe en la relación que se puede establecer entre cristología y antropología.

En el marco de esta cuestión creemos que es necesario asentar el precedente de una recepción crítico-positiva del concepto de sujeto moderno, recuperando su raigambre cristiana, su origen en la reflexión cristológico-trinitaria, que marcó sobre todo los cinco primeros siglos de la era cristiana.

En efecto, los conceptos de persona, de sujeto, de ser-en-relación, que han salido a colación a propósito de la reflexión cristológicotrinitaria, son realidades que dicen bien lo que es el hombre, aunque hoy es necesario plantearlos en relación con la dependencia y al sobrepujamiento con el misterio absoluto, que para el cristiano tiene un rostro concreto en la persona de Jesucristo, verdadero Dios y verdadero hombre.

En este sentido destacamos, por ejemplo, el hecho de que la problemática de la autonomía moderna tenga sus raíces cristianas en el marco de una teología de la creación, la que desacralizando el mundo, comprende a este último como creatura, distinta cualitativamente del creador, posibilitando de este modo una autentica autonomía del mundo.

Desde este estado de cosas, entendemos que la autonomía moderna se ha de comprender en relación con una teonomía cristiana, que posibilita y sobrepuja al ser autónomo. Así lo afirma Walter Kasper, teólogo alemán, que acoge positiva y críticamente el concepto de sujeto moderno en su quehacer teológico, y a quien seguiremos principalmente en estas reflexiones.

Para Kasper (1989a: 225) sólo una teonomía cristiana puede fundamentar y consumar la autonomía de lo creado. Al respecto, el mismo Concilio Vaticano II hace una valoración positiva de la autonomía de lo temporal, expresando en Gaudium et spes n. 36 que esta última es querida por Dios, es expresión de su voluntad, aunque reconoce que dicha autonomía de lo temporal no ha de olvidar su relación de dependencia con el creador. Así las cosas autonomía y teonomía se condicionan recíprocamente. 
Ahora bien, preguntémonos qué significa esto más concretamente en la relación que se puede establecer entre cristología-antropología y cómo la persona de Jesucristo puede responder plenamente a esta cuestión.

La búsqueda o acercamiento a una correcta relación entre Dios y hombre, entre autonomía y teonomía cristiana, la abordaremos en esta reflexión, a partir de tres coordenadas o preguntas, a saber: [1] cómo podemos comprender la realidad humana, el ser del hombre, en el marco del mundo de las relaciones como una alteridad abierta, [2] cómo en Jesucristo se realiza la relación perfecta entre autonomía y teonomía, entre lo trascendente y lo inmanente, y [3] finalmente cómo la individualidad concreta de Jesús de Nazareth se convierte en una experiencia universal, por la acción del Padre en el Espíritu.

\section{El misterio de la alteridad, condición para el encuentro libre}

Si hay una cuestión fundamental en la comprensión de la persona humana es que esta última se entiende dentro del marco de la alteridad. Comprendemos que es en el encuentro libre con el otro, es decir, en la inter-subjetividad, desde donde el hombre se realiza como persona llegando a ser plenamente humano.

Esta experiencia de la alteridad humana, entendida desde el giro antropológico de la época moderna, se desarrolla en el marco de la subjetividad, en la que el sujeto se convierte en el centro de atención. En este punto el dato revelado aporta una cuestión importante, a saber: que la subjetividad se ha de comprender como aquella realidad que no se acaba en sí misma, que no puede cosificar la realidad, sino como aquello que se entiende en el marco de las relaciones, desde la total apertura a todo y al todo (Forte, 2000: 156-160).

Desde esta perspectiva, el hombre no se agota en sí mismo, no puede considerarse como la medida de la realidad sin caer en el sinsentido, debido a que el sentido le viene desde fuera, cuestión que le es imposible encontrar en su realidad finita. De este modo, lo humano, sus búsquedas de libertad, la comprensión de su realidad, creemos necesitan de un nuevo comienzo en la persona de Jesucristo, experiencia que a todas luces le viene desde fuera ${ }^{1}$.

\footnotetext{
1 La encarnación del Verbo en Jesús de Nazareth, es un dato revelado. Expresión de una iniciativa divina que no depende del hombre, sino muy por el contario del puro don, pura gracia.
} 
En el marco del giro antropológico que experimenta la época moderna, el hombre entre otras cosas se comprende como aquel que busca libertad, como aquel que quiere crecer y desarrollarse en espacios de libertad ${ }^{2}$. Esta dimensión de lo humano, su búsqueda y experiencia, no se vive sino en el marco de la inter-subjetividad humana, que no agotándose en lo finito de nuestra experiencia, deja cabida al sujeto absoluto comprendido en sí mismo como libertad en el amor, como aquel que es libertad y como aquel que da el ser en libertad. Este mundo de las relaciones libres, es sustentado y fundado en el ser en sí, que siendo libertad absoluta en el amor hace posible el ser libre del hombre, quien participa del ser por medio de la acción libre del absoluto ${ }^{3}$.

Sin embargo y sin ser ingenuos en nuestra reflexión, creemos que es necesario destacar que nuestra experiencia finita y limitada está marcada por la desgracia, en el sentido de que el hombre vive en la condición espacio-temporal inmerso en situaciones de gracia y de pecado, en medio de la felicidad alcanzada fugazmente y el dolor angustiante que nos hace preguntarnos por el sentido; el ser humano vive en medio de la experiencia de no poder explicarse a sí mismo. A partir de esta situación de contingencia el mensaje cristiano reconoce que en esta situación concreta, el hombre necesita de un nuevo comienzo, entendido éste como redención, como liberación, que no viene desde nuestra inmanencia, sino desde fuera, desde la trascendencia del Otro, que fundamenta y constituye en la existencia.

2 La cuestión de la libertad, la comprensión del ser humano como un ser que busca libertad y liberación, ha sido una búsqueda que ha marcado la cultura moderna, que si bien no la agota, sí se convierte en una cuestión transversal en la experiencia del hombre moderno. En algunos sistemas se ha llegado a negar la relación del hombre con Dios, precisamente por afirmar en el ser humano una autonomía absoluta. En esta problemática, el mensaje cristiano puede y hace un gran aporte, estableciendo un diálogo con la cultura moderna, comprendiendo en el hombre una vocación trascendente, que no se agota en la experiencia finita.

3 Destacamos aquí, que Walter Kasper entiende el ser absoluto como sujeto. Su punto de partida teológico es distinto al de la escolástica, que parte de la concepción del Dios en sí. El punto de partida de este autor es la comprensión de Dios como sujeto libre en el amor, o más bien como el que es libertad en el amor. De este modo y a partir de la comprensión del ser absoluto como sujeto, es posible hablar de un Dios vivo entendido como un ser dinámico, que en su dinamicidad se manifiesta al hombre y le regala el ser. Kasper afirma que Dios, en cuanto libertad absoluta en el amor, al momento de manifestarse y relacionarse en libertad, necesita de una respuesta también libre por parte del hombre. El acto revelatorio en sí mismo es un acto de libertad, por este acto divino se establecen relaciones de libertad en el amor entre Dios y los hombres. El axioma teológico de la escolástica «la Gracia supone la naturaleza» es leído por Kasper en coordenadas de libertad. La naturaleza que supone la Gracia divina es la naturaleza libre del hombre (Kasper, 1989a: 234ss.; 1989b: 280ss). 
Comprendiendo el ser humano como sujeto y particularmente como sujeto libre en el amor, es posible afirmar que la alteridad humana se convierte así en el espacio necesario para el encuentro con el Otro y con los otros, para el encuentro entre estas dos libertades, la divina y la humana, que se condicionan y posibilitan, que se relacionan en la reciprocidad (Kasper, 1989b: 282-284). Este encuentro relacional adquiere dimensiones soteriológicas, toda vez que la relación humanodivina se experimenta como redención-liberación.

En el plano de la alteridad y de la inter-subjetividad, es posible la experiencia del misterio divino en dimensiones existenciales e históricas ${ }^{4}$, en el marco del dato revelado que manifiesta que la experiencia del misterio de Dios se une plena y admirablemente con el misterio del hombre en la persona y en la historia concreta de Jesús de Nazareth. Este encuentro liberador (redentor) entre Dios y hombre, suponen la apertura y la alteridad esencial de lo humano, quien se realiza en el encuentro, personal y libre, con el Otro y con los otros.

Para entender con más profundidad lo que es la experiencia del encuentro inter-subjetivo en el marco de la libre alteridad humana, recurramos al concepto de lo corpóreo en lo humano, aquello corpóreo que asumió el Hijo de Dios en la encarnación. Kasper (2002: 322) afirma: «La acentuación de la corporeidad de la salvación sirve aquí de base a la libertad cristiana». Se trata de acentuar la importancia fundamental de la humanidad de Cristo para nuestra salvación.

En este sentido, la antropología moderna, superando la dualidad griega de cuerpo y alma, se enfrenta hoy a la verdad del hombre, entendiendo la esencia de este último como una unidad, en la que el hombre es totalmente cuerpo y totalmente alma, y ambas son siempre todo el hombre (Kasper, 2002: 325). Concibiendo al hombre en su alteridad, a partir de la unidad que se manifiesta como una identidad personal.

La experiencia corpórea de lo humano, hace del hombre un ser situado en el mundo, lo que forma parte esencial y constitutiva de su ser. Es en esta realidad concreta, donde lo humano experimenta la liberación, el nuevo comienzo, que le viene de la persona de Jesucristo, quien al encarnarse asume toda nuestra condición.

Desde esta perspectiva, la alteridad humana, experiencia-situada-delser, hace posible el encuentro de lo humano con el mundo material y con

\footnotetext{
4 La experiencia del ser contingente y singular, se abre a la experiencia de lo último y definitivo, en la concepción de una historia que se concibe como única y teleológica, como siempre de camino. En esta historia concreta Dios se manifiesta en Jesucristo como el alfa y el omega.
} 
el mundo de los otros, en el marco de la comunión, entendiendo que esta última es posible en el ejercicio de dos libertades que se relacionan en el amor. Destaquemos aquí que el mensaje de Jesús, el anuncio del Reino, es precisamente comunión, unión con Dios y con los demás.

Kasper advierte que desde nuestra realidad situada del ser se desprende el hecho de que nuestra libertad sólo es posible, en concreto, en la relación de aceptación y de respeto por el otro. «La libertad concreta sólo es posible dentro de un orden solidario de libertad, donde cada uno recibe del otro un espacio concreto de vida y libertad» (2002: 327).

Así las cosas, entendemos lo humano como la experiencia del ser que es esencialmente ser-con. Este ser-con, se torna en la expresión y en la realización esencial de lo que es el hombre, que es en lo corpóreo y en lo concreto. Esta realidad situada es la que necesita de redención, entendida ésta como liberación, la que no le viene al hombre desde su inmanencia sino sólo desde fuera, desde un nuevo comienzo en su situación concreta. «Se puede ver claramente en qué medida la realidad de nuestra salvación depende de la venida de Jesucristo a esta situación concreta... la liberación de la situación presente alienante sólo es posible por un comienzo nuevo e indeducible desde dentro de la historia» (Kasper, 2002: 330).

Por el hecho de ser entes situados, será en el encuentro fáctico del hombre con el hombre, y de éste con el mundo, donde se planteará la cuestión de la salvación. Esta situación de salvación, la experiencia de la redención como liberación, se logrará en la medida en que el hombre se abra totalmente a Dios, reconociendo su alteridad.

Debemos llamar la atención, sin embargo, en que así como hay o debe haber una solidaridad en la libertad, existe también una solidaridad pecaminosa, que nos impide ser y reconocernos como plenamente humanos en el encuentro. En efecto, la experiencia del pecado trastoca nuestra situación, convirtiéndola de una situación de gracia, en el plan original de Dios, en una situación de desgracia, como ya lo hemos afirmado. Esta situación de desgracia universal necesita de redención, como experiencia salvadora y liberadora en nuestra situación concreta (Kasper, 2002: 328-335).

Esta liberación cristiana de la situación pecaminosa, sólo es posible por un comienzo nuevo desde dentro de la historia. Un nuevo comienzo que se encarna en la persona de Jesús, quien penetrando en nuestra situación de desgracia la libera. "Jesucristo pertenece al destino ontológico del hombre... Con la venida de Cristo, se ofrece a todo el mundo y a todos los hombres un nuevo kairós, una nueva posibilidad de salvación» (Kasper, 2002: 331). 
Estas reflexiones nos introducen en la capital importancia de la acción salvífica de la verdadera humanidad de Jesucristo, destacando que él es la salvación en su persona corporal. Sólo el hombre nuevo y completo en su humanidad, sólo aquel que es la humanidad plena en sí mismo, puede salvar y liberar al hombre completo, en el cuerpo y en el mundo. Jesucristo es ese hombre nuevo y completo, que en el misterio de la encarnación, ha asumido plenamente nuestra naturaleza humana.

Kasper en su quehacer teológico, llama la atención en que la alteridad humana dice relación a su ser situado y a su ser con-otro, y que es esta realidad concreta de lo humano la que es salvada y liberada por Jesucristo, quien se hizo humanidad plena en la encarnación. A partir del misterio de la encarnación nos sale al encuentro la imagen de un Dios que se preocupa por el hombre en su totalidad.

Asumiendo la necesidad de salvación de toda la experiencia humana, descubrimos que el ser libre y soteriológico de Jesús, hace posible un nuevo comienzo, allí donde la libertad es entendida y vivida en el amor y en la obediencia, expresada hasta la ofrenda de la vida en el misterio de la cruz.

Con lo hasta aquí expresado estamos en condiciones de afirmar que sólo a partir de la alteridad humana, de la experiencia tan nuestra de la inter-subjetividad, reconociendo al Otro y a los otros como tales, será posible la experiencia del encuentro del hombre con Dios.

Este encuentro liberador es posibilitado por la acción divina, es una gracia, en la que Dios se manifiesta en la misma experiencia de lo humano y no al margen de ella. En efecto, cuando Dios quiere comunicarse con el hombre, lo hace en su mundo, en su situación existencial y en su propia historia.

Lo humano, por gracia, se convierte así en el lugar de encuentro con Dios, posibilitando la experiencia del absoluto en la misma contingencia. Dios se revela en Jesucristo en nuestra propia realidad situada, elevando nuestra experiencia de la apertura a lo distinto, salvando y elevando nuestra experiencia de lo personal.

Kasper sostiene que en la experiencia del encuentro, las relaciones humano-divinas se realizan dinámicamente en el misterio de la libertad, entendida ésta última, no como una parte del ser en sí o del ente, sino como la esencia tanto del sujeto absoluto como del contingente ${ }^{5}$. En este

5 Nuestro autor comprende el ser como esencia libre, en el sentido que la «existencia es libertad». El ser en sí, es libertad absoluta, que puede donar el ser en libertad y que además puede ser garante de las relaciones libres del ser contingente, quien recibe el ser como lo dado libremente. Creemos que estamos en condiciones de afirmar que el concepto y la realidad de la libertad, es un campo rico donde la filosofía moderna de la subjetividad y la teología cristiana pueden entablar un diálogo crítico y 
sentido, podemos afirmar que la acción de Dios, en cuanto libertad absoluta, quiere y requiere de una respuesta libre por parte del hombre.

Desde una teología de la creación es posible afirmar que el ser de lo humano, en cuanto que es imagen y semejanza de Dios, se funda y se realiza en y por la libertad en el amor. El creador y la criatura comparten la libertad amorosa, agápica; el primero como una realidad absoluta y el segundo como un don, que es mediado y situado por su condición histórica.

\section{Trascendencia e Inmanencia a la luz del acontecimiento de Cristo}

Para comprender del mejor modo, además que con justicia, a la persona de Jesucristo hemos de entender su ser en sí en relación al misterio trinitario, en la medida en que comprendemos que Jesús de Nazareth es la encarnación del Hijo de Dios, segunda persona de la Santísima Trinidad. Sólo a partir de este dato revelado, será posible afirmar que Jesús de Nazareth es la expresión humana del Hijo encarnado y salvador universal.

En relación a lo anterior, podemos afirmar que el misterio de la encarnación es un acontecimiento histórico único y excepcional, que es capaz de unir la trascendencia del absoluto y la inmanencia de lo humano de un modo admirable, en una sola experiencia humana, la de Jesús de Nazareth.

Asumiendo que la historia es única y teleológica, que responde a categorías espacio-temporales, podemos decir que cuando Dios interviene en ella manifestando su libertad-amor, se convierte en una única historia universal de salvación. En efecto, no existen dos historias paralelas, la de Dios y la de los hombres, sino una única historia, la humana, en la que Dios graciosamente decide revelarse plenamente en la

positivo. En efecto, para la teología cristiana las relaciones personales en el Dios, uno y trino, y las relaciones personales del hombre con Dios y de los hombres entre sí, exigen de por sí la verdad y la existencia de lo libre en Dios y en el hombre. Dios crea y se revela en libertad, porque es el ser libre por antonomasia, es el Dios vivo que necesita de una respuesta libre del hombre, en la fe y en la conversión. Confirmamos con el autor la propuesta, en diálogo con la cultura moderna, en torno a superar el esquema de la metafísica clásica, por una metafísica de la libertad, por una metafísica del amor, relacional. (1989b: 296) Desde la que el sujeto, a partir de su experiencia fáctica, descubre la necesidad de la libertad, y desde lo fáctico puede llegar al ser en sí, manifestado en lo histórico-concreto. El ser en sí es concebido como libre y como quien garantiza las relaciones libres de los hombres, en el marco de una unidad fáctica de lo histórico. 
persona de Jesucristo (tal como muestra el Concilio Vaticano II en Dei verbum, n. 4).

En la historia única y particular de Jesús de Nazareth, creemos que lo humano y lo divino se unen de modo admirable, dando pie a declarar desde el misterio de la encarnación, la unicidad del acontecimiento histórico en general. Dios actúa y se manifiesta en nuestra única historia humana, y en la unicidad del acontecimiento de Cristo en particular.

Desde esta perspectiva creemos que es posible destacar lo concreto del acontecimiento salvífico y la verdad de que Dios no actúa al margen nuestro, sino todo lo contrario, en comunión con nosotros, acogiendo y llevando a plenitud nuestras grandes búsquedas en la persona de Jesucristo. «La unidad en Jesucristo no es una simbiosis natural, sino la unidad y comunión entre hombre y Dios cualitativamente única e insuperablemente personal» (Kasper, 1989c: 319).

Al constatar que nuestra constitución humana es abierta, en el sentido de que está llena de nuevas experiencias y que lo humano se experimenta como aquello no acabado que busca plenitud y trascendencia, podemos afirmar que la experiencia contingente de lo humano, que en cuanto abierta busca trascendencia en su inmanencia, se realiza plenamente y encuentra lo que busca, sólo en el misterio del Dios encarnado (Kasper, 2001: 108ss; 2002: 343.395-398).

A partir de lo anterior, la novedad del mensaje cristiano radica en que precisamente es esta y desde esta situación concreta y ambigua, de desgracia universal, desde donde el Hijo encarnado viene a redimir, experimentando la acción salvadora de Dios en Cristo como liberación, la que por supuesto no depende de nosotros.

Desde este fenómeno concreto queda al descubierto para nuestro autor cómo el anhelo de trascendencia por parte del hombre, necesita de redención (comprendida y experimentada como liberación); por lo que las afirmaciones cristológicas tendrán siempre para el hombre pretensiones salvíficas (Kasper, 2001: 187-192).

En efecto, el trabajo teológico y cristológico, no tienen otra finalidad que explicitar la realidad salvífica del dato cristiano. Desde esta clara finalidad, podremos expresar la necesidad de que en la relación entre Dios y los hombres, deba existir la intervención de un mediador, de un único mediador, como lo reconoce el Nuevo Testamento en la persona de Jesucristo (1Tim 2,5).

Será entonces a partir de este mediador y en él, desde donde se realizará admirablemente la unidad de Dios y del hombre. «Él es el reino de Dios, el amor de Dios en persona que se comunica... Dios obra en su amor sin prescindir ni saltarse al hombre» (Kasper, 2002: 368). 
Constatamos pues a la luz del misterio de la encarnación, que será en la historia de Jesús de Nazareth desde donde se esclarecerá el misterio de Dios y el misterio del hombre. «En él se ve claro qué significa la divinidad de Dios y la esencia humana del hombre» (Kasper, 2002: 168). Ésta es una cuestión de vital importancia en la medida que comprendemos que en la persona de Jesús el Cristo, se afirman cuestiones fundamentales sobre su ser y su significado salvador ${ }^{6}$.

En él, en su encarnación, se unen el cielo y la tierra, y en esta unidad se desarrolla el significado soteriológico de su persona, que en cuanto tal está abierta al Padre. En efecto, la vida y el ser de Cristo se entienden en relación con el Padre desde la eternidad, como el Hijo eterno, y desde su ser humano, como el Hijo encarnado.

En la unidad con el Padre, Jesús se convierte en el camino que nos conduce a Él, se convierte en el mediador entre Dios y los hombres (Jn 14,6; 1Tim 2,5). Esta unidad-comunión entre Jesús y su Padre son las que tienen características personales y relacionales (Kasper, 1989c: 313-317; 2002: 372).

Las personas divinas se hacen tales en la relación entre ellas, relaciones que se viven en unidad y en comunión, en la aceptación de que la persona es en alguna medida mediación para que el otro sea.

Desde esta perspectiva personal y relacional creemos que es posible afirmar que aquel que ha sido mediación personal desde la eternidad, también lo es en el tiempo, en cuanto media entre Dios y los hombres. «La mediación entre Dios y hombre en Jesucristo sólo se puede entender desde la perspectiva teológico-trinitaria» (Kasper, 2002: 403).

Será a partir del misterio trinitario, desde donde podamos comprender que el ser personal no es una realidad cerrada en sí misma, sino todo lo contrario, una realidad que se hace tal en la apertura total al otro, que no disminuye ni anula, sino que más bien constituye. En este sentido, la relación personal entre el Padre y el Hijo, y entre Dios y los hombres no anula, sino que constituye en el ser. Así las cosas, el Padre no anula al Hijo y en el Hijo no anula a los hijos adoptivos.

Esta dimensión relacional de lo personal hace posible que el anhelo de plenitud por parte del hombre (esencia abierta), que lo trasciende por

\footnotetext{
6 Abogamos aquí por la unidad del misterio de Cristo, en lo que la cristología ha formulado como la realidad existencial y funcional de Cristo. Afirmamos con Kasper que conforme a la unidad del acontecimiento hemos de unir en lo más profundo el ser de Cristo en sí y el ser de Cristo para nosotros. No debe haber separación entre lo que se ha llamado cristología esencial y cristología funcional, si las distinguimos es sólo por cuestión de método, salvando la unidad en la diversidad. El ser en sí y el ser para nosotros de Cristo son una única y misma realidad. Él es la salvación, Él es el amor encarnado del Padre (Kasper, 1989b: 295-296).
} 
todas partes, se haga realidad en el encuentro con Dios en la persona de Cristo, el mediador. En efecto, lo divino y lo humano se realizan y se encuentran en Cristo, la esperanza del hombre se une con Dios desde su propio ser humanado, identificado absolutamente con lo histórico.

Insistimos en que esta unión no anula sino que constituye y «sobrepuja» (Überbietung) en Cristo lo humano, que en él se ha enaltecido de modo tan admirable. En palabras de Kasper: «La mayor unión posible significa para el hombre al mismo tiempo la suprema realización de la naturaleza humana» (2002: 393).

En Cristo, el trascendente se ha hecho el inmanente superando toda distancia entre creador y creatura, la que no puede ser superada desde lo humano sino sólo desde Dios, y más concretamente desde el Dios de Jesucristo. La unión mediada por Jesucristo, no representa contradicción alguna con lo humano, sino que se manifiesta como su plenitud más profunda (Kasper, 2002: 398).

En cuanto a la posibilidad de que el hombre conozca el ser de Dios y el suyo propio, hemos de afirmar que esto sólo le es posible en la historia, en el tiempo y en el espacio. Así las cosas, Dios que quiere hablar al corazón del hombre, le hablará en su ser, en su espacio y en su tiempo, en su propia historia, la que asume plenamente en el misterio de la encarnación.

A partir de lo dicho, podemos constatar que aquel que trasciende nuestra historia se manifiesta en el ser histórico inmanente de Cristo, el Hijo encarnado, quien se revela a la vez como la exégesis de Dios y la exégesis del hombre (Jn 1,18). «Conocemos tanto al hombre como a Dios sólo en y desde la historia, los conocemos en su concreción definitiva sólo por razón de la historia y destino de Jesús de Nazareth» (Kasper, 2002: 395).

\section{Cristo en cuanto universal concreto}

Recordando que el punto de partida teológico de nuestro autor es la realidad de Dios entendida como sujeto libre en el amor, hemos recurrido a los conceptos de persona, de relación y de apertura de lo humano, para destacar la dinamicidad de la relación Dios-hombre, que se hace realidad en el ser y en el significado de la persona de Cristo. De este modo, Jesucristo no sólo es modelo de divinidad y de humanidad, sino que él es en sí mismo lo humano y lo divino, aquel que une de manera admirable e insuperable estas dos formas de existencia en su propio ser histórico. 
En su propio ser, Cristo es el que media entre lo trascendente y lo inmanente, entre creador y creatura, no como realidades antagónicas sin relación alguna, o como realidades que se anulan en la unión, sino más bien como experiencias del ser que se interrelacionan y que actúan en dependencia e independencia libre en el amor. El Concilio de Calcedonia (año 451) afirma en este sentido: "Que se ha de reconocer a un solo y mismo Cristo Señor, Hijo unigénito en dos naturalezas, sin confusión, sin cambio, sin división, sin separación. La diferencia de naturalezas de ningún modo queda suprimida por su unión...» [La cursiva es nuestra] (Denzinger \& Hünermann, 2000: 302).

A partir de esto último, a saber, en la relación que se puede establecer entre el misterio cristológico-trinitario y la antropología podemos afirmar con toda propiedad que Jesucristo es el universal concreto, es decir, aquel que en su historia concreta realiza la universalidad de lo divino y de lo humano. En él se realiza definitivamente en la historia lo que significa ser Dios y lo que significa ser hombre.

Podemos reconocer en Jesucristo, a la luz del Espíritu, la plenitud reveladora de lo que es Dios y lo que es el hombre. Cristo revela en el Espíritu la libertad de Dios en el amor, su eterna esencia en las relaciones intra-trinitarias. «El Espíritu llena totalmente la humanidad de Jesús, le comunica el don de la apertura, que le permite ser libremente hueco y vacío total para la autocomunicación de Dios» (Kasper, 2002: 405).

El Espíritu marca la vida del Hijo, en la eternidad y en el tiempo. Hace posible su encarnación y a la vez la liberación espacio-temporal en su resurrección, convirtiendo su concreción histórico-salvífica en universal. «Una orientación pneumatológica puede, pues, interpretar extraordinariamente la unicidad de Jesucristo y su importancia universal. La pneumatología vuelve a situar a la cristología en un horizonte universal» (Kasper, 2002: 407).

Abordamos aquí la importancia de que nuestra salvación sea concreta, en el sentido de que el nuevo comienzo que no depende de nosotros, sino del Otro, se realice también desde nosotros y con nosotros.

En esta perspectiva Kasper resalta la importancia que tiene la humanidad de Cristo para nuestra salvación. Nuestra humanidad se hace plena y nueva en la relación del Hijo con el Padre, se hace nueva porque es sostenida por el Hijo eterno que se encarna en el tiempo y para todos los tiempos.

El Hijo encarnado asume en libertad nuestro ser situados en el mundo, como una determinación esencial de nuestro ser, y desde esta realidad nos ofrece el nuevo comienzo en su persona, el que insistimos no depende de nosotros. 
Será asumiendo nuestra condición de situados, como el Hijo encarnado hace posible un nuevo comienzo, en el que lo humano pueda vivir realmente su identidad y su vocación personal, como relación de comunión con los otros, con el mundo y con el Otro. Se supera así en Jesucristo, la ambigüedad propia de lo humano que necesita de liberación-redención, como ya lo hemos afirmado. Se trata de una comunión o ser-con, que realiza y se realiza en la libertad en el amor, como don del Espíritu (Kasper, 2002: 326-327). «La universalización de la obra de Cristo acontece de una manera espiritual e histórica, determinada por la libertad en el amor» (Kasper, 2002: 419).

Recogiendo los aportes de la antropología moderna, en el sentido de comprender al hombre desde una antropología unitaria (esto es, el hombre como un ser espiritual, o mejor, un espíritu encarnado), valoramos la experiencia situada del ser humano, experiencia que es, o debe convertirse, en un lugar de encuentro con el Otro y con los otros, asumiendo el hombre su vocación original. «Si, a pesar de todo, ha de haber salvación, se necesita un nuevo comienzo, un hombre que penetre en esta situación y la deshaga» (Kasper, 2002: 331).

Al destacar, como lo hemos hecho, que la concreción de nuestro ser está empecatada, tenemos presente que nuestra realidad ambigua está marcada por el egoísmo y no por el amor-comunión que invita al encuentro. Pues bien, es este amor, entendido como comunión entre lo humano y lo divino el que Cristo realiza de modo pleno en su propio ser histórico, en su encarnación (Kasper, 2002: 328-330).

En el misterio de su encarnación, es decir, desde nuestra situación concreta, el Hijo une de modo admirable lo humano con lo divino, en y desde el misterio del amor libre, del amor-comunión: «la realidad de nuestra salvación y de nuestra redención depende de la venida de Jesucristo a esta situación concreta... la redención sólo es posible en cuanto concreta e histórica» (Kasper, 2002: 330). El Hijo encarnado nos muestra en su ser, que lo humano se realiza como tal, en la unión y en la comunión con el Dios que es Padre y creador.

Es a partir del encuentro entre Dios y hombre en Jesucristo, donde lo personal no se vive ya como lo cerrado en sí mismo, sino más bien como aquello que está abierto a la mediación del otro, «del mundo de los otros y del mundo material». Es nuestro ser en relación el que asume el Hijo encarnado, y en su experiencia concreta nos redime y nos libera de nuestra situación de desgracia universal, devolviéndonos nuestra vocación original.

Desde nuestro ser situado, ser marcado por lo histórico, por lo relacional y por lo abierto, nuestro autor llama la atención en que nuestra experiencia humana no es aislada, de que existe una solidaridad en lo 
humano que también es asumida por el Hijo encarnado. Enlazando muy bien con la comprensión del hombre como ser social.

Esta solidaridad humana es atendida por la Sagrada Escritura, afirmando que así como existe una solidaridad en la gracia original, también existe una solidaridad en el pecado ( $R$ m 5,12-19). Desde esta perspectiva destacamos que en la tradición bíblica se revela la necesidad de la intervención de un mediador, que con su acción vicaria remedie el estado de pecado en que se encuentra la humanidad, una situación que como ya hemos dicho debe ser remediada por alguien que siendo desde fuera, por una decisión libre, asuma vicariamente nuestra situación y desde dentro la remedie definitivamente.

Esta solidaridad en la salvación, la tradición veterotestamentaria, la desarrolla en la teología del Siervo sufriente de Yahvé (Is 52,13-53,12), figura que hace referencia a alguien que ha de venir, y que la tradición neotestamentaria encuentra en Jesucristo, el Hijo encarnado, que salva universalmente (Kasper, 2002: 352).

Jesús se convierte así en el hombre solidario, que vicariamente asume nuestro pecado, para redimirnos y liberarnos desde nuestra propia indigencia. Cristo se hace solidario con nosotros por propia iniciativa.

La predicación pospascual acertó con el centro y el sentido de la vida

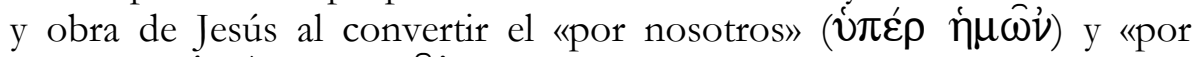

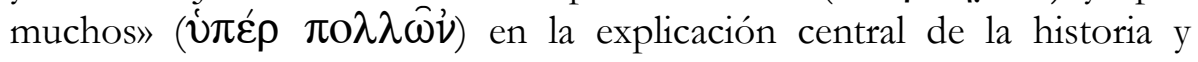
destino de Jesús y definir a este como el hombre «por los demás». Jesús es el hombre solidario por antonomasia (1Cor 15,3- 5; Mc 10,45) (Kasper, 2002: 349).

Desde la fórmula ú $\pi \varepsilon ́ p$, Kasper desarrolla en su cristología un triple significado soteriológico del acontecimiento de Cristo, su entrega se realiza por amor nuestro, en nuestro favor y en nuestro lugar. La solidaridad de Jesús es el centro más íntimo de su ser humano, siendo el hombre para los demás, se transforma no sólo en modelo de humanidad, sino que realiza en él la humanidad verdadera. Una nueva humanidad, que es posible por la acción del Espíritu Santo, concreción personal de la libertad en el amor entre el Padre y el Hijo.

El Hijo encarnado que asume solidariamente nuestra humanidad, realiza su acción solidaria y salvadora a partir de una decisión libre, que es expresada en la tradición bíblica y en la reflexión teológica como una libertad obediente en el amor.

Es así como a partir de la libre solidaridad de la persona de Cristo, nuestra experiencia humana queda redimida y liberada de la esclavitud del pecado. Pecaminosidad que hace que nuestro ser personal se cierre 
en sí mismo, negándose a su ser más íntimo, a su vocación más profunda, a saber: realizarse en la apertura y en la relación con el otro.

En la muerte de Cristo, asumida en libertad solidaria, nuestra humanidad queda liberada de la muerte y de la situación de desgracia, creándose en y desde Cristo una nueva humanidad y un nuevo comienzo. «Jesucristo es no sólo miembro de la humanidad, sino comienzo de una humanidad nueva» (Kasper, 2002: 352).

Esta humanidad nueva en Cristo se manifiesta ahora, en la existencia personal, como mediación de gracia, en la medida en que nuestro ser situado queda determinado por el amor de Dios. Amor que se manifiesta en Cristo reconciliando al hombre con Dios y a los hombres entre sí ${ }^{7}$.

Desde lo que venimos desarrollando es posible afirmar que lo humano en la persona de Cristo, se comprende positivamente como una realidad abierta, que trascendiéndose a sí misma se manifiesta ahora como lo incondicional, como aquello que tiene un valor inapreciable.

Desde el misterio pascual de Jesucristo, la humanidad se manifiesta ahora como aquello que encuentra su plenitud de ser en aquel que superándonos por todos lados, libre y solidariamente decide vivir en nuestra contingencia histórica, sellando esta última con el amor incondicional de Dios, creando así un nuevo comienzo. «Sólo donde el amor de Dios al hombre se convierte históricamente en acontecimiento, sólo entonces puede establecerse un nuevo comienzo en la historia» (Kasper, 2002: 364).

La solidaridad en el pecado, se convierte de este modo por y en Jesucristo en una solidaridad en la gracia, que se manifiesta y se hace realidad en la esencia del Hijo encarnado, el ser para los otros, cuya esencia es autodonación y autoentrega.

El Hijo encarnado realiza libre y solidariamente la mediación entre Dios y los hombres, en relación a Dios como receptividad y en relación a los hombres como entrega solidaria. Su trascendencia en la inmanencia es recepción y entrega (Kasper, 2002: 351). Él es el preexistente que se hace libremente y por amor el proexistente (Schürmann, 2003: 267-301). En Cristo se manifiesta cómo la humanidad llega a su plenitud en la entrega total de la vida. En este sentido el ser humano ha de imitar al Señor Jesús, si quiere alcanzar la plenitud de la vida (Mc 10,45; Jn 15,1213).

La manifestación como Dios y hombre verdadero, hace del Hijo encarnado, el concreto, en la humanidad de Jesús de Nazareth, y el universal en razón de que su ser hombre es asumido y sostenido por el

Kasper (2001: 226-229; 2002: 350) entiende el misterio de la encarnación en sintonía y en profunda comunión con el misterio pascual de Jesucristo. 
Hijo de Dios. En este sentido en Cristo ocurre de una vez y para siempre la reconciliación del mundo.

\section{Conclusión}

$\mathrm{Al}$ partir de lo que hemos expuesto podemos concluir que es posible que nuestra reflexión creyente pueda realizar un diálogo crítico y positivo con la cultura moderna a partir del giro antropológico que esta última ha experimentado. Este es el esfuerzo que realiza en su quehacer teológico Walter Kasper, acogiendo el concepto de «sujeto moderno», en la comprensión del ser desde la subjetividad, mostrando de este modo cómo la relación inter-subjetiva entre Dios y hombre, puede experimentarse dinámicamente, desde el mundo de las relaciones que constituyen la persona. Es uno de los caminos por los que el autor establece la relación entre antropología y cristología. En efecto, el ser divino y el humano, entendidos como sujetos libres en el amor, pueden entablar relaciones de armonía sin que éste último experimente como amenaza al ser divino.

A partir de la concepción de las relaciones subjetivas, que constituyen la persona, podemos leer desde nuevas perspectivas el axioma teológico: «la Gracia supone la naturaleza», en el sentido de que entendiendo el ser divino, como un ser dinámico, libre en el amor, su gracia que es libertad en sí misma, regala el ser en libertad, requiriendo del ser humano una respuesta libre a su graciosa manifestación. La naturaleza que la gracia supone es la libertad del ser en el amor. Una libertad de la creatura que se comprende correctamente siempre en relación con su creador.

La relación de inter-dependencia entre la libertad divina que es en sí misma, y la libertad humana que es donada, en la experiencia individual y concreta de Jesús de Nazareth se torna una experiencia única y excepcional en la que en un sólo ser personal, se vive concreta y paradigmáticamente la armonía de la relación humano-divina. En efecto, en la concreción de la única persona de Jesucristo, el Hijo de Dios encarnado, se muestra, se revela y se manifiesta, el verdadero rostro de Dios y el verdadero ser del hombre, en la experiencia del ser como existencia donada (el preexistente se hace el proexistente). El hombre encuentra en Jesucristo la humanidad plena, que en libertad obediente se muestra y se vive en total dependencia, apertura, y disponibilidad al Padre y a los hombres.

En la relación del Hijo eterno del Padre, que se encarna en Jesús de Nazareth, el ser humano descubre la perfecta humanidad, en Jesucristo 
(universal concreto), el trascendente-inmanente, nos sale al encuentro el Dios de los hombres y la humanidad perfecta que une en relaciones de armonía y sobrepujamiento cristología y antropología.

\section{REFERENCIAS}

-Denzinger, H. \& Hünermann, P. (2000). El magisterio de la Iglesia. (Segunda edición, corregida). Barcelona: Herder.

-Forte, B. (2000). La eternidad en el tiempo. Salamanca: Sígueme.

-Kasper, W. (1989a). Autonomía y teonomía. En W. Kasper, Teología e Iglesia. (págs. 204-240). Barcelona: Herder.

-Kasper, W. (1989b). Cristología y antropología. En W. Kasper, Teología e Iglesia (págs. 266-296). Barcelona: Herder.

-Kasper, W. (1989c). Uno de la Trinidad. En W. Kasper, Teología e Iglesia (págs. 297-321). Barcelona: Herder.

-Kasper, W. (2001). El Dios de Jesucristo. (Sexta edición). Salamanca: Sígueme.

-Kasper, W. (2002). Jesús el Cristo. (Undécima edición). Salamanca: Sígueme.

-Schürmann, H. (2003). El destino de Jesús: su vida y su muerte. Salamanca: Sígueme.

Sumario: Introducción; 1. El misterio de la alteridad, condición para el encuentro libre; 2. Trascendencia e Inmanencia a la luz del acontecimiento de Cristo; 3. Cristo en cuanto universal concreto; Conclusión; Referencias. 